\title{
Chemical vapor deposited SiC (SCS-0) fiber-reinforced strontium aluminosilicate glass-ceramic composites
}

\author{
Narottam P. Bansal \\ National Aeronautics and Space Administration, Lewis Research Center, Cleveland, Ohio 44135 \\ (Received 26 February 1996; accepted 6 November 1996) \\ Unidirectional $\mathrm{SrO} \cdot \mathrm{Al}_{2} \mathrm{O}_{3} \cdot 2 \mathrm{SiO}_{2}$ glass-ceramic matrix composites reinforced with \\ uncoated chemical vapor deposited (CVD) SiC (SCS-0) fibers have been fabricated \\ by hot-pressing under appropriate conditions using the glass-ceramic approach. Almost \\ fully dense composites having a fiber volume fraction of 0.24 have been obtained. \\ Monoclinic celsian, $\mathrm{SrAl}_{2} \mathrm{Si}_{2} \mathrm{O}_{8}$, was the only crystalline phase observed in the matrix by \\ $\mathrm{x}$-ray diffraction. No chemical reaction was observed between the fiber and the matrix \\ after high temperature processing. In three-point flexure, the composite exhibited a first \\ matrix cracking stress of $\sim 231 \pm 20 \mathrm{MPa}$ and an ultimate strength of $265 \pm 17 \mathrm{MPa}$. \\ Examination of fracture surfaces revealed limited short length fiber pull-out. From fiber \\ push-out, the fiber/matrix interfacial debonding and frictional strengths were evaluated \\ to be $\sim 17.5 \pm 2.7 \mathrm{MPa}$ and $11.3 \pm 1.6 \mathrm{MPa}$, respectively. Some fibers were strongly \\ bonded to the matrix and could not be pushed out. The micromechanical models were \\ not useful in predicting values of the first matrix cracking stress as well as the ultimate \\ strength of the composites.
}

\section{INTRODUCTION}

Strong, tough, and environmentally stable fiberreinforced composites (FRC) are needed for various high temperature structural applications in the aerospace and other industries. $\mathrm{BaO} \cdot \mathrm{Al}_{2} \mathrm{O}_{3} \cdot 2 \mathrm{SiO}_{2}$ (BAS) and $\mathrm{SrO} \cdot \mathrm{Al}_{2} \mathrm{O}_{3} \cdot 2 \mathrm{SiO}_{2}$ (SAS) having monoclinic celsian as the crystalline phase are refractory glass ceramics and, therefore, are being used as matrix materials for the fabrication of fiber-reinforced composites at NASA Lewis Research Center. Properties of SiC fiber-reinforced BAS matrix composites have been described earlier. ${ }^{1-3}$ Results of a study on (SCS-0)/ SAS composites are being presented here. The SCS-0 fiber is an uncoated large diameter monofilament produced by chemical vapor deposition. The primary objective of the present study was to develop the processing of SCS-0/SAS composites and characterize their physical and mechanical behavior. Unidirectional fiber-reinforced composites were fabricated by hot-pressing in vacuum. Flexural strengths of the resulting composites were measured in 3-point bending mode, and the fiber/matrix interfacial shear strengths were evaluated by a fiber push-out method. Another objective was to test the applicability of various micromechanical models in predicting the first matrix cracking stress and ultimate strength of the SCS-0/SAS composites.

\section{MATERIALS AND EXPERIMENTAL METHODS}

Strontium aluminosilicate glass of stoichiometric celsian composition, $\mathrm{SrO} \cdot \mathrm{Al}_{2} \mathrm{O}_{3} \cdot 2 \mathrm{SiO}_{2}$, was used as precursor to the matrix. The glass was melted at $\sim 2000^{\circ} \mathrm{C}$ in a continuous electric melter with Mo electrodes using laboratory grade $\mathrm{SrCO}_{3}, \mathrm{Al}_{2} \mathrm{O}_{3}$, and $\mathrm{SiO}_{2}$. Homogeneous and clear glass flakes were produced by quenching the melt between water-cooled metallic rollers. Attrition milling of the glass frit using aluminum or zirconia media resulted in glass powder having an average particle size of $<2.5 \mu \mathrm{m}$. From wet chemical analysis, the composition of the glass powder was determined in weight percent to be $33.7 \mathrm{SrO}$, $31.5 \mathrm{Al}_{2} \mathrm{O}_{3}, 33.8 \mathrm{SiO}_{2}, 0.12 \mathrm{Na}_{2} \mathrm{O}$, and $0.86 \mathrm{BaO}$. The Mo was estimated at $0.01 \mathrm{MoO}_{3}$ by a spectrographic technique. The batch composition in weight percent was $31.8 \mathrm{SrO}, 31.3 \mathrm{Al}_{2} \mathrm{O}_{3}$, and $36.9 \mathrm{SiO}_{2}$, which corresponds to stoichiometric celsian.

Continuous CVD SiC (SCS-0) monofilaments from Textron Specialty Materials having a diameter of $\sim 140 \mu \mathrm{m}$ with no surface coating were used as the reinforcements. These fibers are produced by chemical vapor deposition of $\mathrm{SiC}$ onto a pyrolytic graphite-coated carbon core having diameter of $\sim 37 \mu \mathrm{m}$. The fiber is made up of two distinct zones. The inner zone consists ${ }^{4}$ of carbon-rich $\beta$-SiC columnar grains extending in the radial direction with $\langle 111\rangle$ preferred orientation and lengths of a few micrometers. The outer zone consists of nearly stoichiometric $\beta-\mathrm{SiC}$ grains. The average grain diameter changes from $\sim 50 \mathrm{~nm}$ in the inner zone to $\sim 100 \mathrm{~nm}$ in the outer zone. ${ }^{4}$ At room temperature these fibers typically have an elastic modulus of $\sim 391 \mathrm{GPa}$ and a tensile strength of $\sim 1.8 \mathrm{GPa}$. The average axial thermal expansion coefficient of these fibers, from room temperature to $1000^{\circ} \mathrm{C}$, is $\sim 4.4 \times 10^{-6} /{ }^{\circ} \mathrm{C}$. 
Unidirectional FRC panels $(\sim 11.25 \mathrm{~cm} \times 5 \mathrm{~cm} \times$ $0.125 \mathrm{~cm}$ ) with five plies were fabricated using a glassceramic approach to take advantage of the viscous flow of the glass during hot pressing. Details of this method are described elsewhere. ${ }^{1-3}$ An aqueous slurry of SAS glass powder along with organic additives was cast into tapes using a doctor blade and allowed to dry in ambient atmosphere. The dry tape, $\sim 0.15 \mathrm{~mm}$ thick, was cut to size. The fiber mats were prepared by winding continuous SCS-0 fibers on a drum with a spacing of 41 fibers per $\mathrm{cm}$ and cut to size. Adhesive tape was used to hold the fibers in place. Matrix tapes and fiber mats were alternately stacked up in the desired orientation and warm pressed. The resulting "green" composite was wrapped in Mo sheet and then in grafoil sheet and hot-pressed under vacuum in a graphite die under appropriate pressure and temperature. The fugitive binder was burned out in situ in the hot press by holding at a lower temperature. The resulting FRC panels were surface polished and sliced into flexure test bars using a high speed diamond blade saw.

Microstructures of the polished cross sections as well as fracture surfaces were observed in an optical microscope as well as in a JEOL JSM-840A scanning electron microscope (SEM). X-ray dot mapping of various elements in the fiber/matrix interface region was carried out using a Kevex Delta class analyzer. The fiber volume fraction in the composite, $V_{f}$, was determined from

$$
V_{f}=N_{f} \pi D^{2} / 4 w d
$$

where $N_{f}$ is the number of fibers, $D$ is the fiber diameter assumed to be $140 \mu \mathrm{m}$, and $w$ and $d$ are, respectively, the width and thickness of the specimen. Densities were measured by the Archimedes method as well as from specimen dimensions and weight. The crystalline phases formed in the matrix were identified from powder $\mathrm{x}$-ray diffraction (XRD) patterns recorded at room temperature using a step scan procedure $\left(0.03^{\circ} / 2 \theta\right.$ step, count time $0.5 \mathrm{~s}$ ) on a Philips ADP-3600 automated powder diffractometer equipped with a crystal monochromator and employing $\mathrm{Cu} \mathrm{K}_{\alpha}$ radiation. Mechanical properties were determined from stress-strain curves recorded in threepoint flexure using an Instron machine at a crosshead speed of $0.127 \mathrm{~cm} / \mathrm{min}(0.05 \mathrm{in} . / \mathrm{min})$. The span length of the lower rollers was $3.75 \mathrm{~cm}$ (1.5 in.). A test span to sample thickness ratio of $>25$ was used in strength measurements. The first matrix cracking stress and the elastic modulus of the composites were determined from strain gauges glued to the tensile surface of the test bars. A discontinuous jump in strain in the load versus strain plot indicated matrix cracking. Matrix cracking was also indicated by a kink in the load versus time output of a chart recorder. Values of first matrix cracking stress obtained from the two techniques were in good agreement. Elastic modulus was determined from the linear portion of the load versus strain curve up to the first matrix cracking load.

Fiber/matrix interfacial shear strength was determined from a fiber push-out test ${ }^{5}$ using thin polished sections of the composites cut normal to the fiber axis. The indenter, a $100-\mu \mathrm{m}$ diameter, flat-bottomed tungsten carbide punch was aligned over a single fiber and was driven at a constant speed of $50 \mu \mathrm{m} / \mathrm{min}$. The specimen was supported so that the fiber being pushed out can protrude out of the bottom of the sample without any obstruction. A load cell in parallel with the punch constantly monitors the load as the punch is pushed mechanically. Load data were collected at $50-\mathrm{ms}$ intervals by a computer. Conversion of time to actual crosshead displacement allows a load versus displacement curve to be generated as the output of the push-out test. At least ten fibers were pushed out in different regions of the FRC. The push-out apparatus had an upper load limit of $40 \mathrm{~N}$.

\section{RESULTS AND DISCUSSION}

A scanning electron micrograph of the polished cross section of the SCS-0/SAS FRC is shown in Fig. 1. Uniform fiber distribution and good matrix flow around the fibers during hot pressing is observed. In the hot-pressed composites, the SAS matrix crystallized to the desired thermodynamically stable monoclinic celsian $\mathrm{SrAl}_{2} \mathrm{Si}_{2} \mathrm{O}_{8}$ phase, ${ }^{6}$ as found from XRD analysis (Fig. 2). Typical stress-displacement curve, measured in 3-point flexure, for a unidirectional composite with fiber volume fraction of 0.24 is shown in Fig. 3. Also shown is the stress versus displacement curve, measured in 4point bend, for a SAS monolith hot-pressed at $1200^{\circ} \mathrm{C}$ for $2 \mathrm{~h}$ under $24 \mathrm{MPa}$. The monolith shows a strength

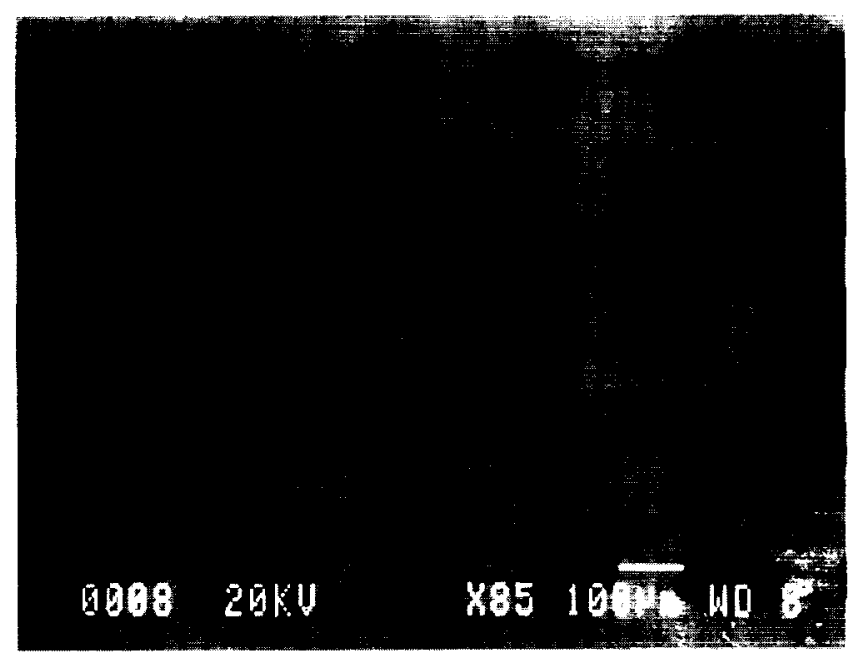

FIG. 1. SEM micrograph of polished cross section of unidirectional CVD $\mathrm{SiC}_{f}(\mathrm{SCS}-0) / \mathrm{SAS}$ composite showing uniform fiber distribution. 


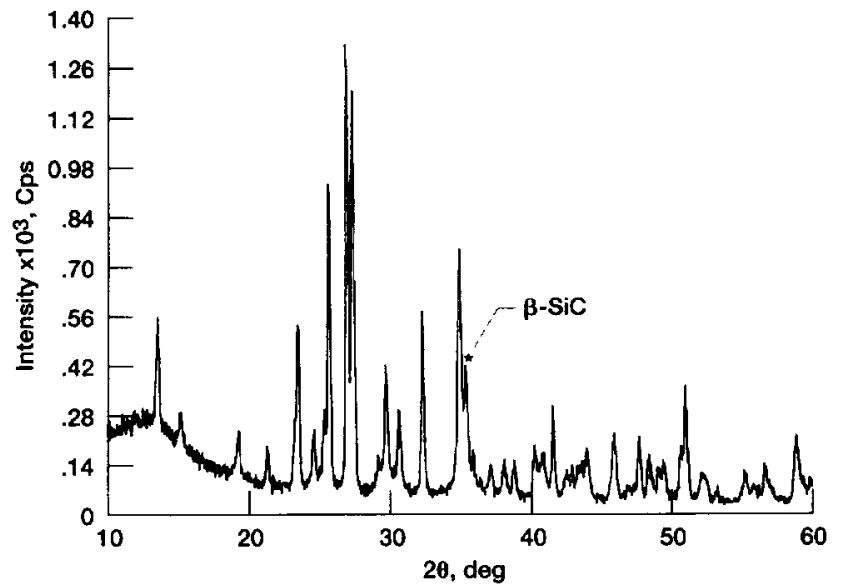

FIG. 2. Powder $x$-ray diffraction pattern of SCS-0/SAS composite. The peak at $2 \theta=35.6$ is due to $\beta-\mathrm{SiC}$. The remaining peaks correspond to monoclinic celsian.

of $\sim 130 \mathrm{MPa}$ and fails in a brittle mode as expected. For the composite, the stress-strain curve consists of an initial linear elastic region followed by first matrix cracking where the applied load reaches a critical value required to propagate the first microcrack across the specimen outer tensile surface layer. Beyond this the load is transferred to the fibers showing some increase in strength beyond the first matrix crack, followed by a large and sudden drop in load. As discussed below, the strength of the SCS-0 fibers degraded during high temperature composite processing, thus limiting loadcarrying capacity beyond the first matrix cracking stress. Room temperature physical and mechanical properties of the composite are summarized in Table I. Average values of first matrix cracking stress, $\sigma_{v}$, and ultimate strength, $\sigma_{u}$, (Table I) of the unidirectional composite for five test bars were $231 \pm 20 \mathrm{MPa}$ and $265 \pm 17 \mathrm{MPa}$, respectively. In contrast, $\mathrm{CVD} \mathrm{SiC}_{f}$ (SCS-6)/SAS composites show ${ }^{7}$ graceful failure with $\sigma_{y}$ of $\sim 289 \mathrm{MPa}$

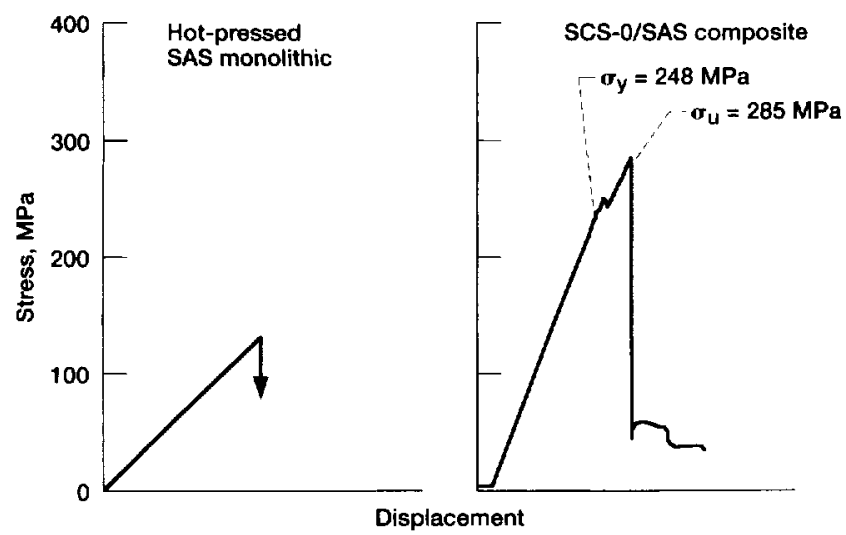

FIG. 3. Stress-displacement curves for hot-pressed SAS monolithic and unidirectional SCS-0/SAS composite $\left(V_{f}=0.24\right)$ measured in four-point and three-point flexure, respectively.
TABLE I. Room temperature properties of unidirectionally reinforced CVD $\mathrm{SiC}_{j}$ (SCS-0)/SAS composites [SAS 6-9-93].

\begin{tabular}{ll}
\hline \multicolumn{1}{c}{ Property } & \multicolumn{1}{c}{ Value } \\
\hline Measured & \\
\hline Fiber volume fraction, $V_{f}$ & 0.24 \\
Density, $\rho, \mathrm{g} / \mathrm{cm}^{3}$ & $2.99^{\mathrm{a}}$ \\
Elastic modulus, ${ }^{b} E, \mathrm{GPa}$ & $102 \pm 10$ \\
First matrix cracking stress, ${ }^{\mathrm{b}} \sigma_{y}, \mathrm{MPa}$ & $231 \pm 20$ \\
First matrix cracking strain. ${ }^{b} \epsilon_{y}, \%$ & $\sim 0.22$ \\
Ultimate strength, ${ }^{b} \sigma_{u}, \mathrm{MPa}$ & $265 \pm 17$ \\
Fiber/matrix debonding strength, ${ }^{c} \tau_{d}, \mathrm{MPa}$ & $17.5 \pm 2.7$ \\
Sliding frictional stress, $\tau_{f}, \mathrm{MPa}$ & $11.3 \pm 1.6$ \\
Calculated & \\
\hline$\sigma_{y}, \mathrm{MPa}$ & 365 \\
Transition crack length, $C_{m}, \mu \mathrm{m}$ & 625 \\
$\sigma_{u}, \mathrm{MPa}$ & 470 \\
\hline \hline
\end{tabular}

a $\sim 98 \%$ of theoretical density.

'From three-point bend test.

'From fiber push-out test.

and $\sigma_{u}$ of $\sim 824 \mathrm{MPa}$. These results clearly demonstrate that reinforcement of the SAS glass-ceramic with SCS-0 fibers results in toughening, but only a very limited improvement in $\sigma_{u}$ beyond the first matrix crack.

To understand fracture mechanism in the composites, one can compare the experimental results with the composite theories. For example, in unidirectional fiber-reinforced composites, the ultimate composite strength may be approximately calculated from the rule-of-mixture equation

$$
\sigma_{u}=\sigma_{f} V_{f}
$$

where the matrix is assumed to carry no load and $\sigma_{f}$ is the average fiber strength (for $25 \mathrm{~mm}$ gauge length) after high temperature composite processing. However, average strength of the fibers in situ in the FRC following hot pressing is unknown unless fibers can be extracted from the composite without further damage to the fibers and tensile tested. It is known that the interactions occurring during the composite processing may reduce the fiber strength. For example, strength of Nicalon fibers is $\sim 3 \mathrm{GPa}$, but strength of the fibers extracted from Nicalon/Pyrex composites following processing at $\sim 950{ }^{\circ} \mathrm{C}$ is reduced by $\sim 50 \%{ }^{8}$ The degradation in the fiber strength depends on the temperature and pressure used during processing as well as on the reactivity between the fiber and the matrix. The strength of SCS-0 fibers degrades ${ }^{9}$ after exposure to temperatures beyond $\sim 1200^{\circ} \mathrm{C}$ in argon, due to recrystallization and grain growth of the $\mathrm{SiC}$ grains in the outer zone of the fibers. Strength degradation of the fibers increased with temperature and time of exposure at temperatures above $1200^{\circ} \mathrm{C}$. For example, the room temperature strength of SCS-0 fibers degraded from $3.2 \mathrm{GPa}$ to $2.5 \mathrm{GPa}$ and 
1.9 $\mathrm{GPa}$ after $1 \mathrm{~h}$ exposure in $0.1 \mathrm{MPa}$ argon pressure at $1400{ }^{\circ} \mathrm{C}$ and $1600^{\circ} \mathrm{C}$, respectively. ${ }^{9}$ The exposure temperature has greater influence on the fiber strength degradation than time. This probably explains the low ultimate strengths observed in the present study for the composite hot-pressed at high temperature.

A typical SEM fracture surface micrograph, after the 3-point bend test, of FRC is shown in Fig. 4. Debonding of the fibers from the matrix at the interface and matrix crack deflection around the fibers are clearly observed. However, only limited short length fibers pull-out is seen in the composite which would result in only limited toughening behavior. The surface of the pulled-out fibers is clean and smooth. These results are consistent with the stress-strain behavior observed for these FRC's. SEM micrographs showing the fiber/matrix interface in FRC's are shown in Fig. 5. The interface is clean and no gross reaction is observed at the fiber/matrix interface.

To further analyze the interface behavior, typical load versus crosshead displacement curves for push-out of fibers from the composite are shown in Fig. 6. The initial linear region corresponds to the elastic response of the test apparatus. The peak load, $P_{\text {debond }}$, corresponds to the fiber/matrix interfacial shear strength, and the sudden drop in load represents debonding of the fiber. Following debonding, the slight increase in load corresponds to additional debonding. At the maximum, the entire length of the fiber is debonded and the fiber begins to exit from the opposite face of the composite. The slow decrease in load is due to the decrease in embedded length of the fiber. The steady state load represents the sliding friction at the interface. Assuming a uniform interfacial shear stress along the length of the fiber/matrix interface, values of the interfacial shear strength for debond $\left(\tau_{d}\right)$

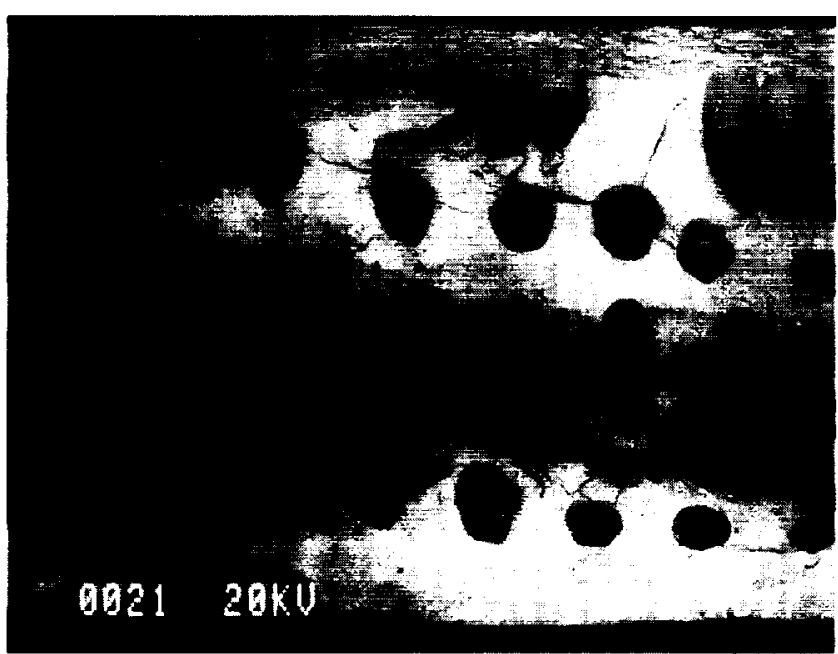

FIG. 4. SEM micrograph of the fracture surface of a unidirectional SCS-0/SAS composite showing limited tiber pull-out.
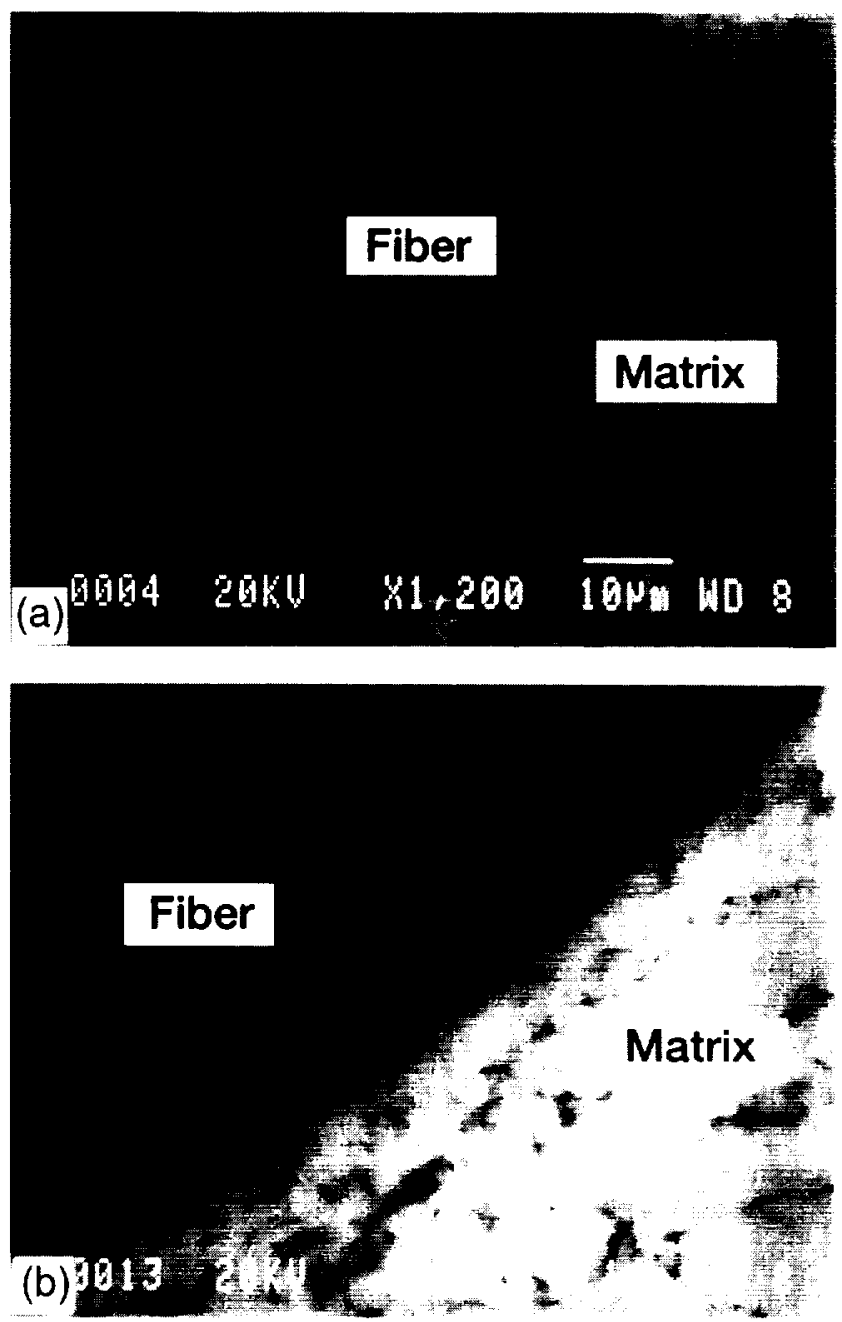

FIG. 5. (a, b) SEM micrographs of the polished cross section of a unidirectional SCS-0/SAS composite showing the absence of chemical reaction at the fiber-matrix interface

and frictional resistance $\left(\tau_{f}\right)$ were evaluated from

$$
\tau=P /\left(2 \pi r L_{f}\right)
$$

where $P$ is the debonding or frictional load, $r$ is the fiber radius, and $L_{f}$ is the embedded fiber length. The mean values of $\tau_{d}$ and $\tau_{f}$ (Table II) were determined to be $17.5 \pm 2.7 \mathrm{MPa}$ and $11.3 \pm 1.6 \mathrm{MPa}$, respectively. One fiber even gave a value of $56 \mathrm{MPa}$ for $\tau_{d}$. Some fibers did not debond even at a load of $40 \mathrm{~N}$, the upper limit of the test apparatus, resulting in $\tau_{d}>62 \mathrm{MPa}$. Values of $\tau_{d}$ and $\tau_{f}$ are seen to be much higher for the SCS-0/SAS composite than $6.6 \pm$ $0.7 \mathrm{MPa}$ and $4.2 \pm 0.6 \mathrm{MPa}$ observed for the SCS-6/ SAS system. ${ }^{10}$ From fiber push-out and pull-out tests, the fiber/matrix interfacial shear strengths have been evaluated to be $15.6 \pm 8.3$ for the SCS-0 fiber and $3.9 \pm$ 1.4 for the SCS-6 fiber in a borosilicate (CGW \#7761) glass matrix. "Signs of chemical reaction between the 

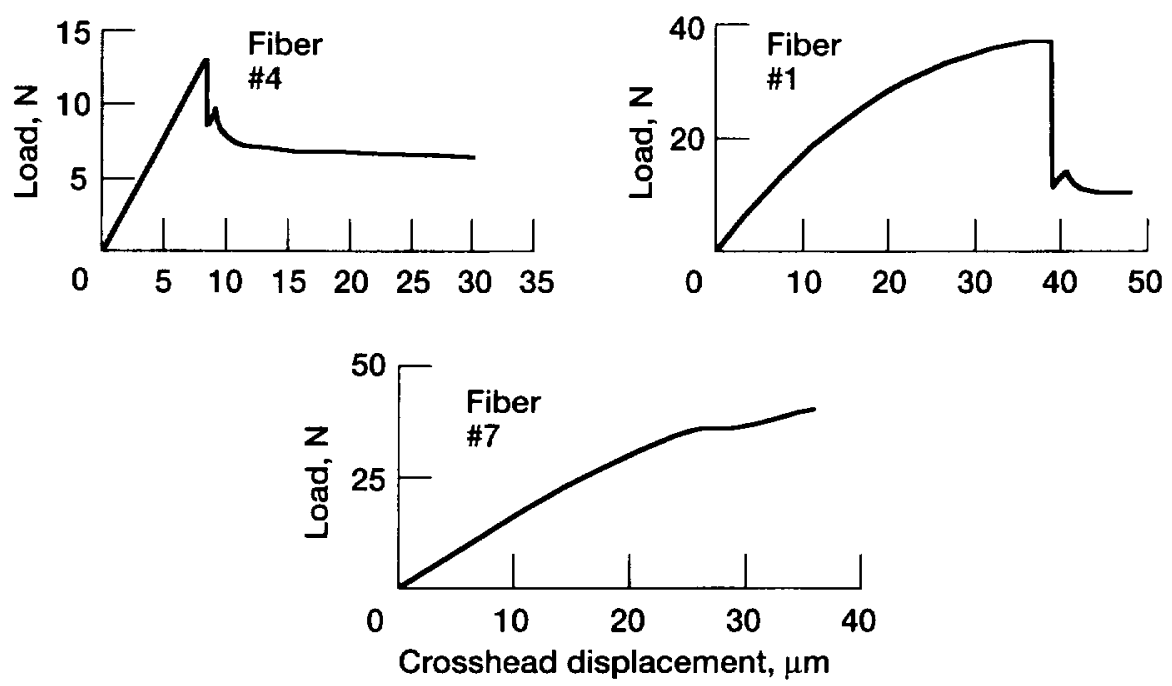

FIG. 6. Typical load versus crosshead displacement curves recorded during fiber push-outs in CVD SiC $($ (SCS-0)SAS composites; sample thickness $1.44 \mathrm{~mm}$.

uncoated SCS-0 fiber and the glass were observed after composite processing, whereas no reaction was observed between the glass and the SCS- 6 fiber having carbonrich surface coatings. Goettler and Faber ${ }^{12}$ measured the fiber/matrix interfacial shear properties of $\mathrm{SiC}$ fibers in sodium borosilicate glass matrix system using single fiber pull-out tests. A carbon coating on the SiC fiber surface was an effective reaction barrier in preventing the fiber/matrix bonding and oxidation of the fibers by the glass matrix. However, coatings having higher carbon content resulted in stronger bonding at the interface.

SEM micrographs showing the in-plane and pushedout fibers in the composite are shown in Fig. 7. The

TABLE II. Fiber push-out data for CVD $\mathrm{SiC}_{f}$ (SCS-0)/SAS composite [SAS 6-9-93; $V_{f}=0.24$; sample thickness $=1.44 \mathrm{~mm}$.

\begin{tabular}{ccccc}
\hline $\begin{array}{c}\text { Fiber } \\
\text { No, }\end{array}$ & $\begin{array}{c}\text { Debond } \\
\text { load, N }\end{array}$ & $\tau_{d,}$, MPa & $\begin{array}{c}\text { Sliding } \\
\text { load, N }\end{array}$ & $\tau_{j}, \mathrm{MPa}$ \\
\hline $1^{\mathrm{a}}$ & $36.03^{\mathrm{h}}$ & $56.1^{\mathrm{h}}$ & 10.0 & 15.6 \\
2 & 11.55 & $18.0^{\mathrm{h}}$ & 7.07 & 11.0 \\
3 & 9.05 & 14.1 & 6.75 & 10.5 \\
4 & 13.14 & 20.4 & 6.84 & 10.6 \\
5 & 12.17 & 18.9 & 7.13 & 11.1 \\
6 & 13.98 & 21.8 & 7.60 & 11.8 \\
$7^{\mathrm{c}}$ & $>40^{\mathrm{h}}$ & $>62^{\mathrm{h}}$ & & \\
8 & 10.09 & 15.7 & 6.81 & 10.6 \\
9 & 9.89 & 15.4 & 6.54 & 10.2 \\
10 & 10.28 & 16.0 & 6.85 & 10.7 \\
$11^{\mathrm{b}}$ & $>40^{\mathrm{h}}$ & $>62^{\mathrm{h}}$ & & \\
Mean: & 11.27 & 17.5 & 7.29 & 11.3 \\
Std. Dev.: & 1.73 & 2.7 & 1.06 & 1.6 \\
\hline \hline
\end{tabular}

${ }^{\mathrm{a}}$ This fiber showed atypical behavior; however, the data are real and the fiber did debond.

bot included in taking the mean.

"Fiber did not debond up to a load of $40 \mathrm{~N}$. the upper limit of the apparatus.
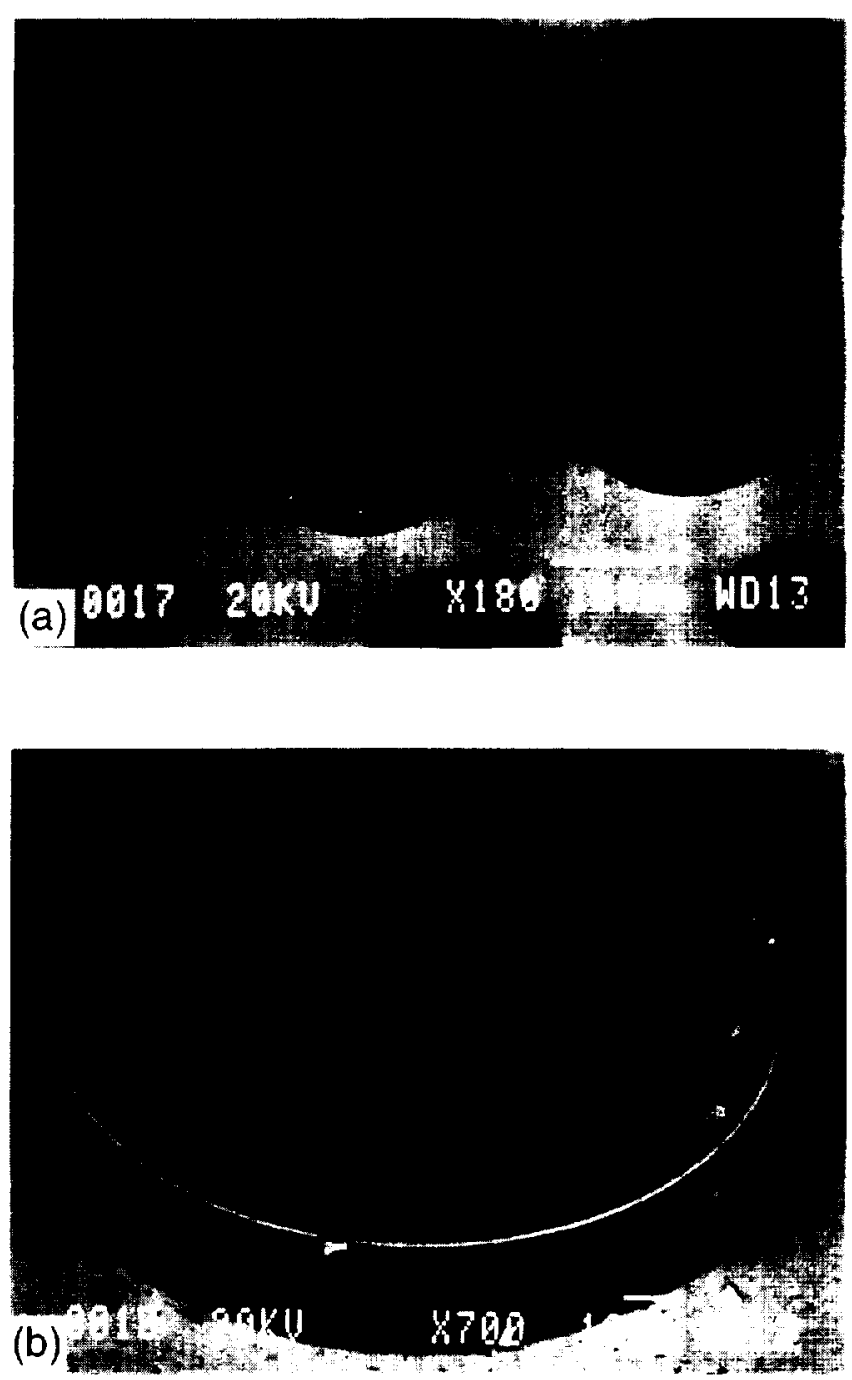

FIG. 7. (a,b) SEM micrographs showing in-place and pushed-out fibers in $\mathrm{CVD} \mathrm{SiC}_{f}(\mathrm{SCS}-0) / \mathrm{SAS}$ composite. 
surfaces of the pushed-out fibers appear to be smooth. There appears to be clean debonding between the fibers and the matrix. Also, no chemical interaction is observed at the fiber/matrix interface after the high temperature composite processing. An SEM micrograph and the $x$-ray dot maps of various constituent elements taken on the polished surface of the sample in the fiber/matrix region are presented in Fig. 8 . On this scale, there appears to be no interdiffusion of the elements between the fiber and the matrix after high temperature composite processing. In an earlier study by the present author, ${ }^{13}$ no chemical reaction was observed between the SCS-0 fiber and BAS matrix in hot-pressed composite. Examination of the fracture surface revealed fiber/matrix debonding at the interface, fiber pull-out, and crack deflection around the fibers, indicating a weak fiber/matrix interface and a tough composite. Murthy and Lewis ${ }^{14}$ reported the formation of a carbon-rich layer at the fiber/matrix interface in $\mathrm{SiC}$ (Nicalon or Tyranno) fiber-reinforced nonstoichiometric BAS composite hotpressed at $1350^{\circ} \mathrm{C}$. The reaction layer was an admixture of microcrystalline graphite, silica, and baria. Extensive diffusion of barium well into the fiber was also observed. In contrast, the $\mathrm{SiC}$ whisker/BAS glass interface was found to be nonreactive.
It is also interesting to compare the measured value of first matrix cracking stress with those predicted from the steady-state micromechanical models which have been recently developed. Using fracture mechanics analysis, Marshall, Cox, and Evans ${ }^{15}$ have modeled matrix cracking in brittle matrix fiber-reinforced composites by taking into account the crack closure effects of the frictionally bonded bridging fibers. For large cracks, the matrix cracking stress is independent of the crack size, and a steady state matrix cracking stress is given by ${ }^{15}$ :

$$
\begin{aligned}
\sigma_{y}= & 1.817\left[\left(1-\nu^{2}\right) K_{l C}^{2} \tau_{f} E_{f} V_{f}^{2} V_{m}\right. \\
& \left.\times\left(1+E_{f} V_{f} / E_{m} V_{m}\right)^{2} /\left(E_{m} r\right)\right]^{1 / 3}
\end{aligned}
$$

where $\nu$ is the composite Poisson's ratio, $K_{I C}$ the matrix fracture toughness, $V_{m}$ the matrix volume fraction, $r$ the fiber radius, $E_{f}$ the fiber elastic modulus, $E_{m}$ the matrix elastic modulus, and the other terms have been defined earlier. Using $\nu=0.2, \quad K_{I C}=1 \mathrm{MPa} \cdot \mathrm{m}^{1 / 2}, \quad E_{f}=$ $390 \mathrm{GPa}, V_{f}=0.24, E_{m}=69 \mathrm{GPa}, V_{m}=0.76$, and $r=71 \mu \mathrm{m}$, Eq. (4) may be written as $\sigma_{v}=53.8\left(\tau_{f}\right)^{1 / 3}$. Using $\tau_{f}=11.3 \pm 1.6 \mathrm{MPa}$ for the composite in the present study, a value of $121 \mathrm{MPa}$ is predicted for $\sigma_{y}$ from Eq. (4) without making any corrections for the expected residual stresses in the matrix arising from
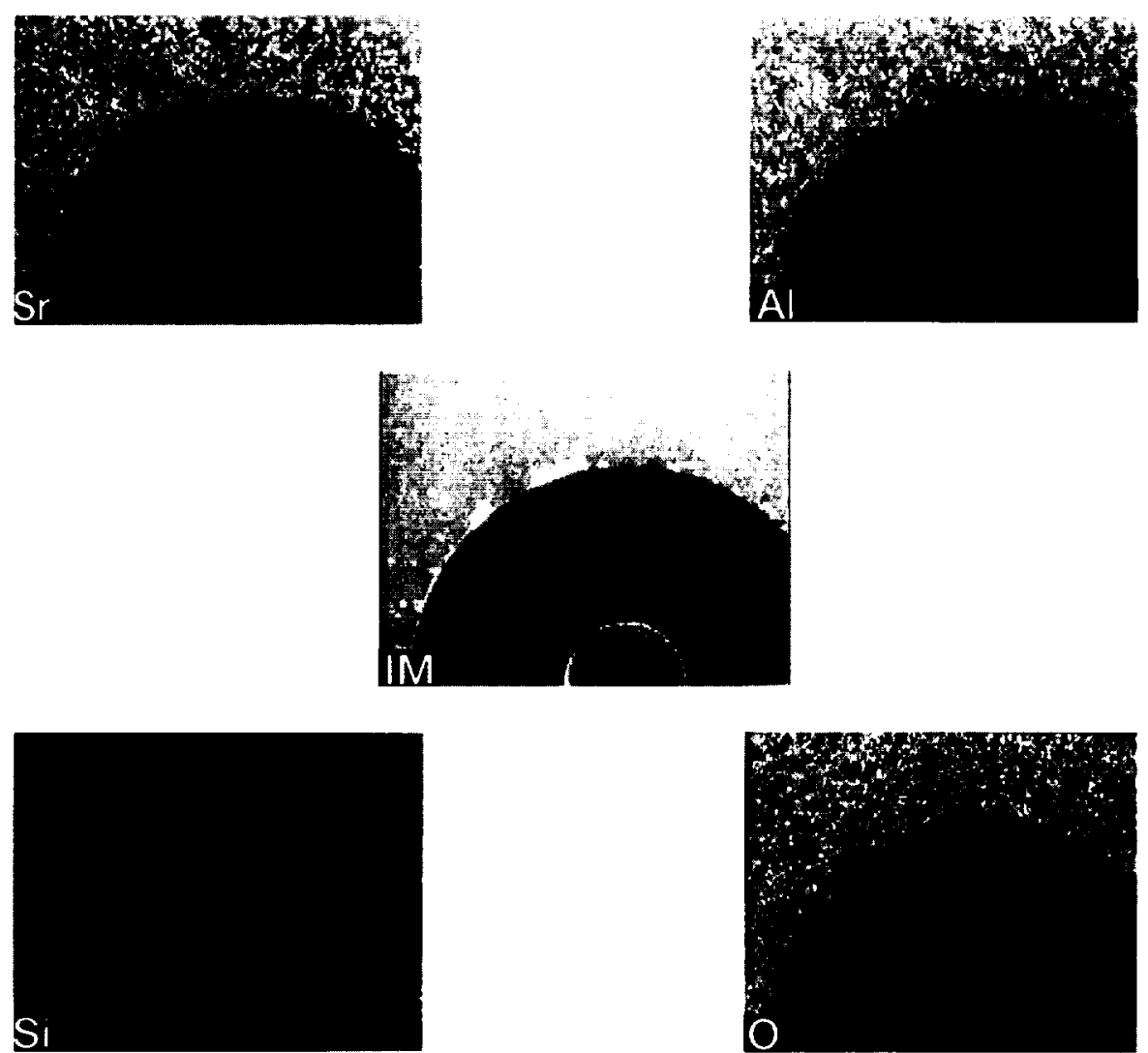

FIG. 8. SEM micrograph and $x$-ray dot maps of various elements at the fiber-matrix interface of the polished cross section of a unidirectional CVD $\mathrm{SiC}_{f}(\mathrm{SCS}-0) / \mathrm{SAS}$ composite. 
the thermal expansion mismatch between the fiber and the matrix. This calculated $\sigma_{v}$ is significantly lower than the measured 3-point bend strength of $231 \pm$ $20 \mathrm{MPa}$. However, it may be pointed out that generally the tensile strengths are lower than those measured in bending and the tensile test results, rather than the flexural data, are more meaningful for comparison with the predictions of the micromechanical models. Also, Eq. (4) estimates the lower bound $\sigma_{y}$ at large crack lengths above the transition crack length, $C_{m}$, which is given by the following equation:

$$
C_{m}=\left(\pi / 4 I^{4 / 3}\right)\left\{\left(K_{I C} r E_{m} V_{m}\right) /\left[\tau_{f} V_{f}^{2} E_{f}\left(1-\nu^{2}\right)\right]\right\}^{2 / 3},
$$

where $l$ is a crack geometry constant with a value of 1.2 for straight cracks and $2 / 3$ for penny cracks. The expression for $C_{m}$ given in the original work of Marshall et $a l^{15}$ appears to be in error. Using Eqs. (23a) and (17b) from Ref. 15, the above Eq. (5), rather than that reported in the paper by Marshall et al. ${ }^{15}$ is obtained for $C_{m}$. The matrix cracking stress approaches the steady state value for cracks of lengths $\geqslant C_{m} / 3$. In contrast, for cracks shorter than $C_{m}, \sigma_{y}$ should show a marked dependence on crack size and significant departure from the steady-state $\sigma_{x}$. Using the above values for various parameters, the value of $C_{m}$ calculated for the SCS-0/ SAS composite from Eq. (5) was $379 \mu \mathrm{m}$. Since the $C_{m} / 3$ value for this composite is near the SCS-0 filament diameter, this would indicate significant departure from the steady-state matrix cracking stress and a marked dependence on the crack size. $C_{m}$ values of $313 \mu \mathrm{m}$. $68 \mu \mathrm{m}, 660 \mu \mathrm{m}$, and $3500 \mu \mathrm{m}$ have been reported for the Nicalon/lithium aluminosilicate glass-ceramic, ${ }^{15}$ carbon/glass, ${ }^{15} \mathrm{SiC}(\mathrm{SCS}-6) /$ zircon, ${ }^{16}$ and $\mathrm{SiC}(\mathrm{SCS}-6) /$ sodium-zirconium phosphate $(\mathrm{NZP})^{17}$ composites, respectively. This implies that $C_{m} / 3$ is several fiber spacing for all these composites, indicating the existence of a steady-state condition. Since the inherent flaws in ceramic materials are usually of microstructural dimensions, these results indicate ${ }^{15}$ that the matrix cracking stress for these composites is not considerably reduced by further introduction of larger flaws during composite fabrication or service or by the extension of pre-existing flaws in thermal shock or environmentally assisted slow crack growth.

The above analysis suggests that the first matrix cracking stress measured in the present study is not controlled by a crack-bridging mechanism, but by Griffith fracture of as-produced flaws under the combination of applied and residual stresses. However, it may be pointed out that the effects of residual thermal stresses arising from the thermal expansion mismatch between the fiber and the matrix have not been taken into account in the calculations of the model. The axial residual stress in the matrix, $\sigma_{m}$, present in the composite as a result of cooling from the hot pressing temperature is given by ${ }^{19}$

$$
\begin{aligned}
\Delta \sigma_{m} & =\left[E_{f} V_{f}\left(\alpha_{m}-\alpha_{f}\right) \Delta T\right] /\left[1+V_{f}\left(E_{f} / E_{m}-1\right)\right] \\
& =\left[E_{f} V_{f}\left(\alpha_{m}-\alpha_{f}\right) \Delta T\right] \cdot\left[E_{m} / E_{c}\right]
\end{aligned}
$$

where $\alpha_{m}$ and $\alpha_{f}$ are the thermal expansion coefficients of the matrix and the fibers, respectively, $\Delta T$ is the temperature range over which the composite has cooled after hot-pressing, and the other terms are the same as described above. For the composite of this study, with $V_{f}=0.24, \alpha_{f}=4.4 \times 10^{-6} /{ }^{\circ} \mathrm{C}, \alpha_{m}=$ $2.5 \times 10^{-6} /{ }^{\circ} \mathrm{C}, E_{f}=390 \mathrm{GPa}$, and $E_{m}=69 \mathrm{GPa}$, the axial residual stress, $\Delta \sigma_{m}$, in the matrix at room temperature is calculated from Eq. (6) to be $-115 \mathrm{MPa}$. The negative $\Delta \sigma_{m}$ implies that the SAS glass-ceramic matrix will be in compression as fibers try to shrink more than the matrix and the residual stresses will be beneficial, tending to close the incipient matrix cracks. The residual stress in the composite, $\Delta \sigma_{c}$, due to thermal expansion mismatch between the fiber and the matrix is given by:

$$
\Delta \sigma_{c}=\Delta \sigma_{m}\left(E_{c} / E_{m}\right)=\left[E_{f} V_{f}\left(\alpha_{m}-\alpha_{f}\right) \Delta T\right]
$$

For the SCS-0/SAS composite, value of $\Delta \sigma_{c}$ is calculated to be $-244 \mathrm{MPa}$ from Eq. (7). To account for the residual stress effects due to fiber-matrix thermal expansion mismatch, $\Delta \sigma_{c}$ calculated from Eq. (7) should be added to that determined from Eq. (4) resulting in $\sigma_{y}$ of $365 \mathrm{MPa}$, which is much higher than the $231 \pm 20 \mathrm{MPa}$ measured in 3-point bend. Also, the tensile test results, rather than the flexural data, are more meaningful for comparison with the predictions of the micromechanical models and generally the tensile strengths are lower than those measured in bending. This would result in greater discrepancy between the predicted and the measured tensile strength data. Hence, the micromechanical models do not appear to be useful in predicting the first matrix cracking stress for the SCS-0/SAS composite.

The ultimate tensile strength of a fiber-reinforced composite is given by the equation ${ }^{20.21}$ :

$$
\begin{aligned}
\sigma_{u}= & V_{f} \sigma_{f}\left[\{1 /(m+2)\}^{1 / m+1 /}\{(m+1) /(m+2)\}\right] \\
& \times\left[2 \tau_{f} L_{0} /(\ln 2) \sigma_{f} r\right]^{1 / m+1},
\end{aligned}
$$

where $V_{f}$ is the volume fraction of fibers in the loading direction, $\sigma_{f}$ is the mean fiber tensile strength at a gauge length of $L_{0}, m$ is the Weibull modulus, and other terms have been described earlier. Equation (8) takes into account the proper gauge length of fibers relevant to composite tensile failure as well as the fiber bundle failure in brittle matrix composites. In Eq. (8), the first two terms, $V_{f} \sigma_{f}$, give the rule-of-mixtures strength of the composite using the mean fiber strength at the test gauge length $L_{0}$. The third term within brackets is the statistical bundle-like factor depending only on $m$. This factor describes the tendency of the statistically 
weaker fibers to control the composite failure and the counteracting fact that broken fibers still have substantial load-carrying capability due to the sliding resistance $\tau_{f}$. Thus, the first three terms together essentially give the bundle rule-of-mixtures strength of the FRC. The last term, called the composite factor, in Eq. (8) accounts for the change in fiber strength from gauge length $L_{0}$ to the characteristic gauge length relevant to composite tensile failure and for the load carried by the broken fibers in brittle matrix composites. The composite factor is critical for predicting an accurate value of $\sigma_{u}$ for the composite. Tensile strengths of SCS-0 fibers have been recently measured by the present author. ${ }^{22}$ Taking $\sigma_{f}=2686 \mathrm{MPa}, m=6.2, L_{0}=1.25 \mathrm{~cm}, r=70 \mu \mathrm{m}$, and $\tau_{f}=11.3 \mathrm{MPa}, V_{f}=0.24$ for the SCS-0/SAS composite, a value of $\sigma_{u}=470 \mathrm{MPa}$ was calculated from Eq. (8). The calculated value of $\sigma_{u}$ is much higher than the measured 3-point flexure strength of $265 \pm$ $17 \mathrm{MPa}$. This is particularly true considering that the ultimate strengths of composites measured in flexure are reported $d^{23,24}$ to be always higher than those measured in tension, by a factor of between 1.5 and 2.5 , depending on lay-up. This is generally ascribed to the differences in stress distributions in the test specimens during flexure and tensile tests. During tensile testing, the entire gauge section is under tensile loading, but only a part of the sample is under tension during flexure test. Thus, the flexure strength data are not very useful for comparison with the predictions of the micromechanical models which are based on the assumptions of uniaxial tensile loading. Another reason for the discrepancy between the measured and predicted values of $\sigma_{u}$ could be the fiber strength degradation occurring during composite fabrication due to high temperature exposure and abrasion damage, as discussed above.

\section{SUMMARY OF RESULTS}

Unidirectional CVD SiC (SCS-0) fiber-reinforced SAS glass-ceramic matrix composites have been fabricated by hot-pressing. An almost fully dense composite with fiber volume of $24 \%$ showed a first matrix cracking stress of $231 \pm 21 \mathrm{MPa}$ and an ultimate bend strength of $265 \pm 17 \mathrm{MPa}$. The fracture surface showed only limited and short length fibers pull-out. No chemical reaction between the fibers and the SAS matrix was observed from microstructural observations and EDAX analysis after high temperature processing. From fiber push-out tests, the fiber/matrix debonding stress was found to be $17.5 \pm 2.3 \mathrm{MPa}$, indicating a weak interface. Some of the fibers were strongly bonded and could not be pushed out. It is not clear why some fibers are weakly bonded and the others are strongly bonded with the matrix in the composite. The micromechanical models do not appear to be useful in predicting the first matrix cracking stress and the ultimate strength for the large diameter CVD SiC (SCS-0) fiber-reinforced SAS glass-ceramic matrix composite.

\section{v. CONCLUSION}

It may be concluded that reinforcement of SAS glass-ceramic with uncoated CVD SiC (SCS-0) fibers results in only limited improvement in load-carrying capacity beyond the first matrix cracking stress. Thus, the SCS-0 fiber is not very useful as a reinforcement for SAS glass-ceramic matrix.

\section{ACKNOWLEDGMENTS}

Thanks are due to John Setlock and Richard First for their assistance in composite processing and testing.

\section{REFERENCES}

1. N.P. Bansal, Ceramic Fiber Reinforced Glass-Ceramic Matrix Composite, U.S. Patent 5214004 , May 25, 1993.

2. N.P. Bansal, Method of Producing a Ceramic Fiber-Reinforced Glass-Ceramic Matrix Composite, U.S. Patent 5281559 , January 25, 1994.

3. N.P. Bansal, SiC/Celsian Glass-Ceramic Matrix Composites, HITEMP Review 1991: Advanced High Temperature Engine Materials Technology Program, NASA CP-10082, 1991, pp. 75-1 to $75-15$.

4. F. W. Wawner, A. Y. Teng, and S. R. Nutt, SAMPE Quart. 14 (3), 39-45 (1983).

5. J.I. Eldridge, R.T. Bhatt, and J.D. Kiser, Investigation of Interfacial Shear Strength in $\mathrm{SiC} / \mathrm{Si}_{3} \mathrm{~N}_{4}$ Composites, NASA TM-103739, 1991.

6. N.P. Bansal and C. H. Drummond III, J. Am. Ceram. Soc. 76 (5), $1321-1324$ (1993).

7. N.P. Bansal, Fiber-Reinforced Refractory Glass-Ceramic Composites, in HITEMP Review 1993: Advanced High Temperature Engine Materials Technology Program, Vol. III-Turbine Materials-CMCs, Fibers, NASA CP 19117, p. 63-1 to 63-13 (1993).

8. K. M. Prewo, J. Mater. Sci. 21 (10), 3590-3600 (1986).

9. R. T. Bhatt and D. R. Hull, Microstructural and Strength Stability of CVD SiC Fibers in Argon Environment, NASA TM 103772, 1991.

10. N.P. Bansal, CVD Silicon Carbide Monotilament Reinforced SrO-Al $\mathrm{O}_{3}-2 \mathrm{SiO}_{2}$ (SAS) Glass-Ceramic Composites, NASA TM $106992,1995$.

11. A. J. G. Jurewicz, R. J. Kerans, and J. Wright, Ceram. Eng. Sci. Proc. $10(7-8), 925-937$ (1989).

12. R. W. Goettler and K.T. Faber, Composites Sci. Technol. 37 (1-3), 129-147 (1989).

13. N.P. Bansal, Processing and Properties of CVD SiC FiberReinforced $\mathrm{BaAl}_{2} \mathrm{Si}_{2} \mathrm{O}_{8}$ Glass-Ceramic Matrix Composites, in Proc. of 17th Conference on Metal Matrix, Carbon, and Ceramic Matrix Composites, Cocoa Beach, FL, Jan. 10-15, 1993; NASA Conference Publication 3235, Part 2, pp. 773-797 (1994).

14. V.S.R. Murthy and M. H. Lewis, Br. Ceram. Trans. J. 89 (5), $173-174$ (1990).

15. D. B. Marshall, B. N. Cox, and A. G. Evans, Acta Metall. 33 (11), 2013-2021 (1985)

16. R. N. Singh, J. Am. Ceram. Soc. 73 (10), 2930-2937 (1990).

17. C. W. Griffin, S. Y. Limaye, D. W. Richerson, and D. K. Shetty, Ceram. Eng. Sci Proc. 11 (9-10), 1577-1591 (1990). 
18. B. Budiansky, J. W. Hutchinson, and A. G. Evans. J. Mech. Phys. Solids 34 (2), 167-189 (1986).

19. D. C. Phillips, R. A. J. Sambell, and D. H. Bowen, J. Mater. Sci. 7, 1454-1464 (1972)

20. W. A. Curtin, J. Am. Ceram. Soc, 74 (11), $2837-2845$ (1991).
21. W. A. Curtin, Composites 24 (2), 98-102 (1993)

22. N.P. Bansal, unpublished research.

23. R. N. Singh, J. Mater. Sci. 26 (23), 634I-635I (1991).

24. S. M. Bleay, V. D. Scott, B. Harris, R. G. Cooke, and F. A. Habib. J. Mater. Sci. 27 (10), 2811-2822 (1992) 
